METAgraphias: letra G de \#GOROROBA e outras abobrinhas v.2 n.4 dezembrol2017

(...) só não pode morrer na praia • Luisa Günther (luisagunther@gmail.com)

\title{
(...) só não pode morrer na praia
}

Luisa Günther ${ }^{1}$

${ }^{1}$ Faz um google aí.

ISSN 2448-1246 

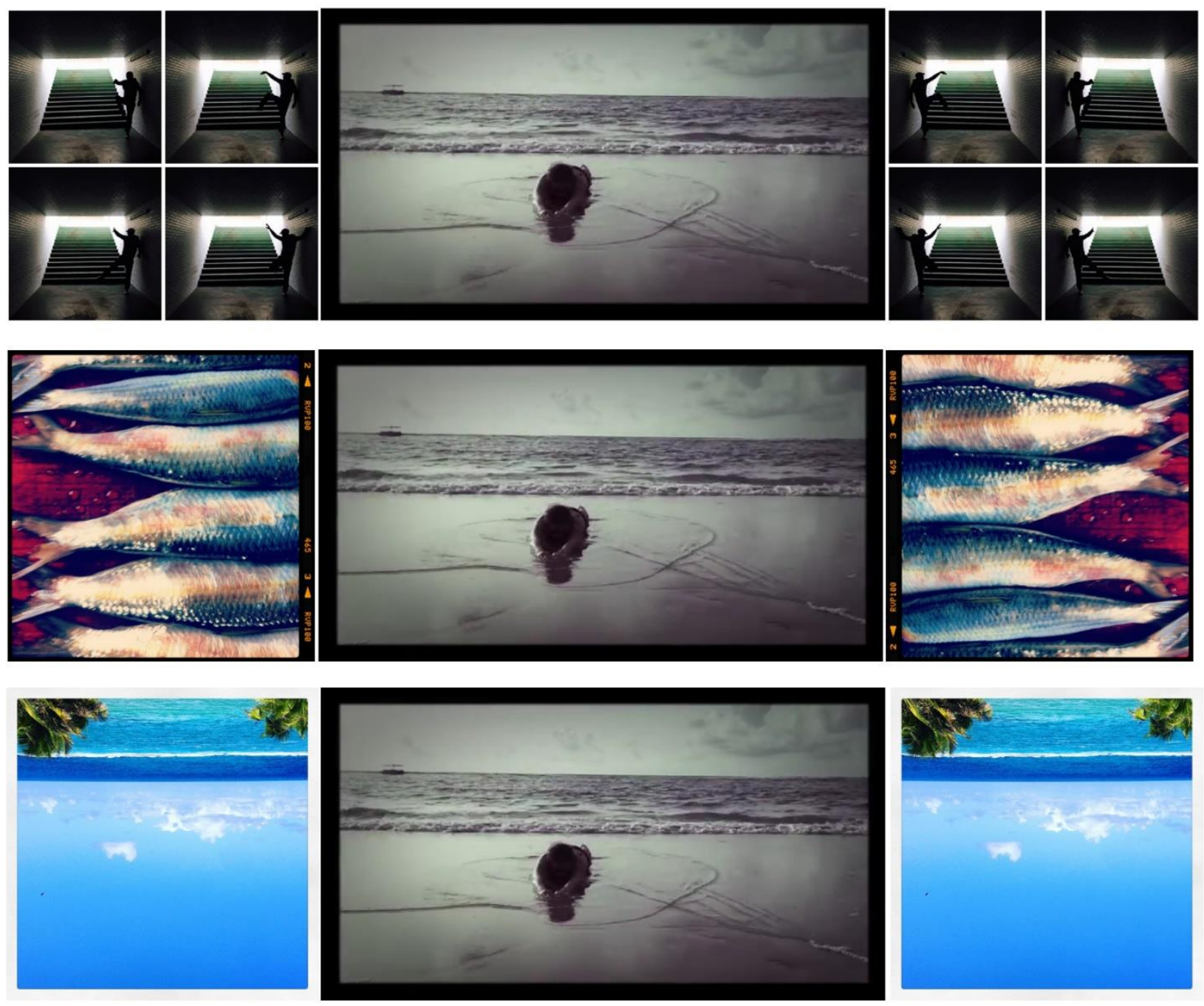
METAgraphias: letra G de \#GOROROBA e outras abobrinhas v.2 n.4 dezembrol2017

(...) só não pode morrer na praia • Luisa Günther (luisagunther@gmail.com)

Prezada curadoria,

(...) puxa! A proposta de elaborar um tríptico para a vídeo-dança "só não pode morrer na praia" (2016) a partir de uma composição fotográfica resultou em um algumas possibilidades. Confesso que escolher é sempre um pouco mais difícil do que fazer. Em todo caso,

1. a primeira relação de sentido foi formalista a partir da sensação de profundeza e sufocamento; de luz e sobra; de textura: como se cada onda do mar fosse um degrau que encontra um corpo disponível a existir entre a profundeza e a superficialidade; entre o limite do ar e a possibilidade de respiração.

2. (...) sentido semântico imediato: como se o nadar fosse uma ação deslocada entre a areia da praia e a tábua de cortar carne. Caudas de sardinha poderiam ser o rabo de uma sereia?! Aquilo que está fora d'água na fotografia já cumpriu o ciclo simbólico daquilo que não deveria acontecer na vídeo-dança?!

3. (...) sentido de disparidade e inversão <ou> de estranhamento e complementariedade óbvia entre aquilo que fica à nossa volta enquanto o esforço de manter-se no absurdo de uma ação desnecessária: para quê tanto esforço?! Basta ficar de pé e olhar para o céu, que já se contorce para fitar de volta o que acontece sob seu domínio pleno em um dia de sol paradisíaco. $\mathrm{O}$ azul é para todos?!

4. (...) sentido alegórico: para que o imponderável não nos consuma em sua dimensão mais apocalíptica é preciso ter sorte. Haja mandinga!

5. (...) sentido inevitável: já que todos vamos morrer, que seja na praia. Que a nossa morte nos redima de nós mesmos por entre as condições necess'årias de nossa mais plena redenção, por mais herege que seja a nossa prece. Ao bem da verdade, na hora do sufoco, não existem ateus.

6. (...) sentido contraposto: esta dupla realiza uma pesquisa que dimensiona o registro e a polaridade entre suporte e movimento. À vídeo-dança "só não pode morrer na praia" é repelido a foto-dança "em terra de cobra coral o fogo só arde quando queima". Assim o ciclo de tudo o que é possivel, para além do imediato, poderia ser própria a metafísica como o refúgio político: os quatro elementos e os três poderes.

título: [dicas sobre como elaborar uma poética dialética com o contexto <ou> quanto mais incompreensão, tanto mais necessárias as possibilidades infinitas, mesmo que sejam apenas seis]. 


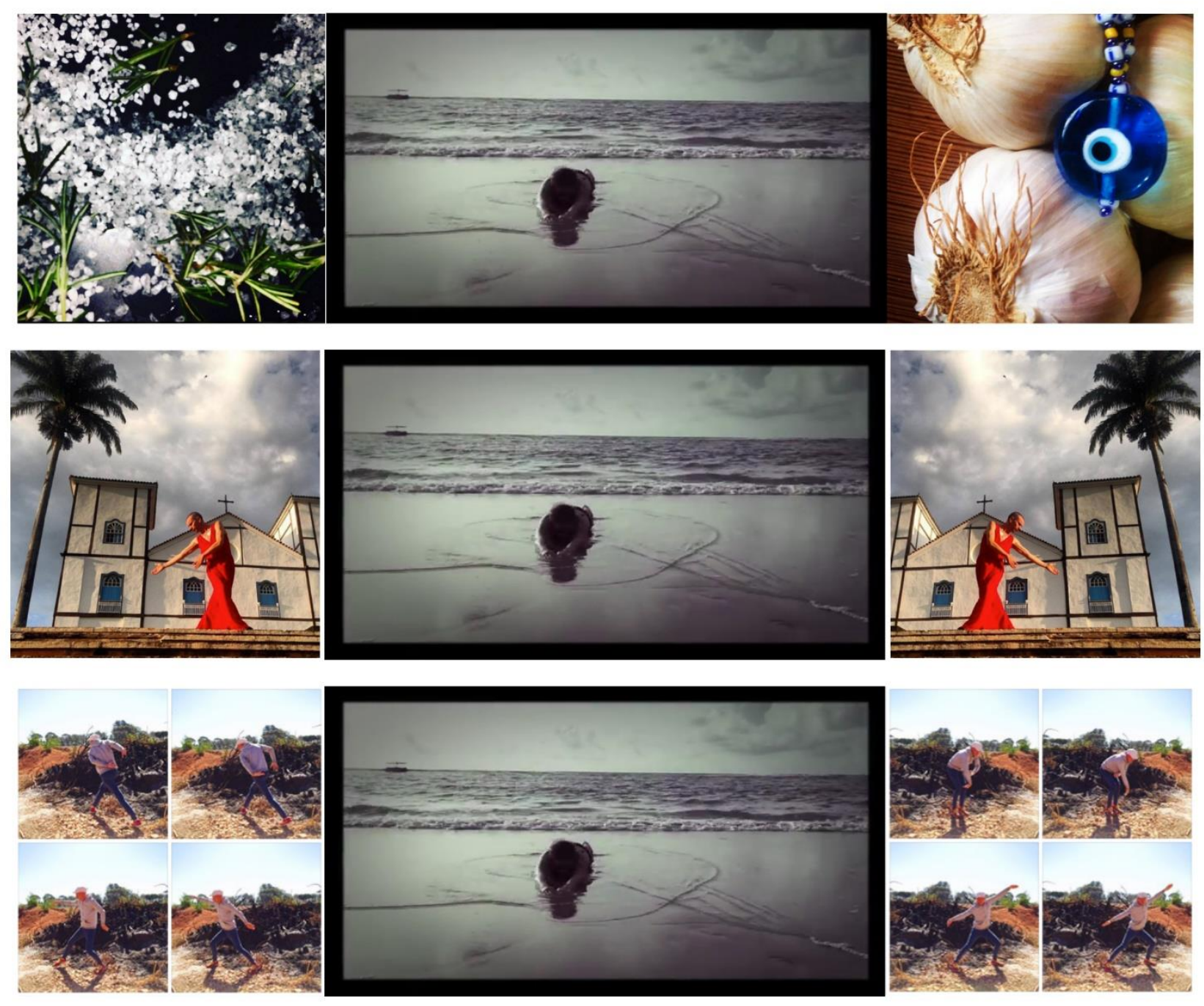

